\title{
A Case of Pulsatile Tinnitus Caused by Idiopathic Intracranial Hypertension in the Female Obese Patient
}

\author{
Eui-Cheol Nam ${ }^{1,2}$, Yoon-Jong Ryu ${ }^{2}$ \\ 'Department of Otolaryngology, College of Medicine, Kangwon National University, Chuncheon, Korea \\ ${ }^{2}$ Department of Otolaryngology, Kangwon National University Hospital, Chuncheon, Korea \\ 젊은 고도비만 여성에서 발생한 특발성 두개내고혈압 기원의 박동성 이명 1 예 \\ 남 의 철,2. 유 윤 종 ${ }^{2}$ \\ 강원대학교 의학전문대학원 이비인후과학교실', 강원대학교병원 이비인후과 ${ }^{2}$
}

\begin{abstract}
Purpose: Tinnitus is a common but troublesome symptom that often interferes with daily life and its treatment has not yet been established. However, pulsatile tinnitus can be cured in most cases when the related anatomical or functional cause is removed. Idiopathic intracranial hypertension $(\mathrm{IIH})$ commonly manifests with headache, nausea, vomiting, pulsatile tinnitus and diplopia, while no structural lesion or vascular abnormality is identified in the intracranial cavity. Methods: We discuss a case of a 23-year-old woman who complained of pulsatile tinnitus by IIH and was successfully treated with carbonic anhydrase inhibitor (acetazolamide). Results: In Korea, incidence of IIH-induced pulsatile tinnitus is low, which might be due to the fact that high degree obesity is not common compared with western countries. Particular caution is necessary because the diagnostic work-up for pulsatile tinnitus in Korea may not routinely include screening for IIH-related symptoms and signs. Conclusion: We therefore report this case with a review of existing literature.
\end{abstract}

Key Words: Tinnitus, Idiopathic intracranial hypertension, Obesity.

Received: January 4, 2018 / Revised: January 12, 2018 / Accepted: January 13, 2018

Correspondence: Yoon-Jong Ryu, Department of Otolaryngology, Kangwon National University Hospital, 156 Baengnyeong-ro, Chuncheon 24289, Korea Tel: +82-33-258-2311 / Fax: +82-33-258-9486 / E-mail: skyland17@gmail.com

\section{INTRODUCTION}

박동성 이명은 환자 자신만이 들을 수 있는 감각신경성 이명 과는 달리 단속적이고 맥박과 일치하는 양상의 이명이며, 대부 분 혈관에서 기인하는 이명으로서 혈류의 증가 또는 혈관의 협 착에 의해 와류가 발생할 때 들리게 된다. 대개 저음역대의 소리 가 환자의 맥박과 일치해서 들리며 외부의 움직임 또는 자세의 변화에 따라 이명 크기가 변하는 특징을 보인다. 특히 일측성인 경우는 동정맥 누공(arteriovenous fistula), 혈관류(aneurysm), 종양 등의 기질적 원인이 있을 수 있으며, 이는 생명에 지장을 줄 수 있고 그 원인이 되는 질환을 치료하면 이명도 소실되기 때 문에 정확한 진단과 적절한 치료의 시행이 매우 중요하다. 정맥 성 이명의 경우 경정맥구의 골결손이나 고위경정맥구(dehisence or high jugular bulb) 같은 경정맥구의 이상과 S상 정맥동게실 (sigmoid sinus diverticulum) 같은 해부학적인 이상이 가장 흔 하다. 그러나 혈관의 이상과 직접적인 연관성이 없으면서 심장 박동과 같은 리듬으로 들리는 아주 희귀한 박동성 이명의 경우 도 있다. 그중에서 두통과 불규칙한 월경 증세를 동반한 젊은 비만 여성에게 발생한 경우 그 원인이 두개 내압의 상승과 관련 이 있다고 알려져 왔으나 아직까지 우리나라에서는 이와 같은 증례가 보고된 바가 없다.

\section{MATERIALS AND METHODS}

본 논문에서는 젊은 여성에서 특별한 혈관의 구조적 이상이 없이 발생한, 특발성의 두개내고혈압에 따른 박동성 이명 1 예 를 문헌 고찰과 함께 보고하고자 한다. 


\section{RESULTS}

23세 여자 환자가 4개월 전에 시작되어 3주 전부터 심해진 우측 귀의 이명을 주소로 강원대학교병원 이비인후과 외래에 내원하였다. 이명의 양상은 간헐적이었으며 심장의 박동과 유 사한 리듬으로 느껴지는 박동성이었으며, 과거력에서 두부 외 상의 병력은 없었다. 이경검사에서 외이도, 고막, 중이강 등은 모두 정상 소견으로 관찰되었다. 경부 청진 시 들리는 혈관 잡음 은 없었으며 손가락으로 양측 경정맥을 압박하였을 때 이명의 강도가 증가하는 양상이었다. 청력검사상 순음청력검사(Figure $1 \mathrm{~A})$ 와 고막운동성검사는 정상 소견이었으며 이명도검사상 음 조는 $125 \mathrm{~Hz}$, 음량은 $30 \mathrm{~dB}$ 에 매칭되며 규칙적인 주기를 보이 는 박동성 이명으로 확인되었다. 측두골컴퓨터단층좔영(temporal bone $\mathrm{CT}$ )에서도 외이, 중이, 내이 유양동과 경정맥 및 경 동맥에 이상 소견은 관찰되지 않았다. 따라서 저자들은 우선적 으로 약물치료 시행을 고려하였고 심박 수와 심박출량을 낮추
고 혈압을 안정적으로 유지하여 박동성 이명의 1 차 치료 약물로 흔히 사용되는 beta blocker (프로프라놀롤 $10 \mathrm{mg} \mathrm{bid}$ )를 경구 처방하였다. 1 주 후 환자의 이명은 완전히 소실되어 이후 약물 사용을 중단하고 경과 관찰하였다.

이로부터 약 5 개월 후 환자는 2주 전부터 발생한 어지럼증 및 두통을 주소로 외래에 다시 내원하였다. 천장이 빙글 도는 양 상의 어지럼증이 2주 전부터 시작하였고 두통이 동반되었으며 이전에 있었던 이명은 더욱 크게 들려서 좌측에서도 소리가 난 다고 하였다. 이외에 다른 이과적 증상은 동반되지 않았고 특징 적으로 증상의 악화가 생리주기와 거의 일치한다고 하였다. 비 디오안진검사를 이용한 전정기능검사에서 특이 소견은 없었으 며 순음청력검사상 처음과 달리 저음역에서 5 10 dB의 청력저 하가 관찰되었다(Figure 1B). Beta blocker에 추가로 이뇨제인 dichlozid와 isobide를 2주 투여하였으나 이명 및 어지럼증, 두 통이 지속되었다. 환자가 매우 비만한 가임기 젊은 여성이고 두 통이 지속적으로 동반되며 일반적인 박동성 이명 치료 약제에
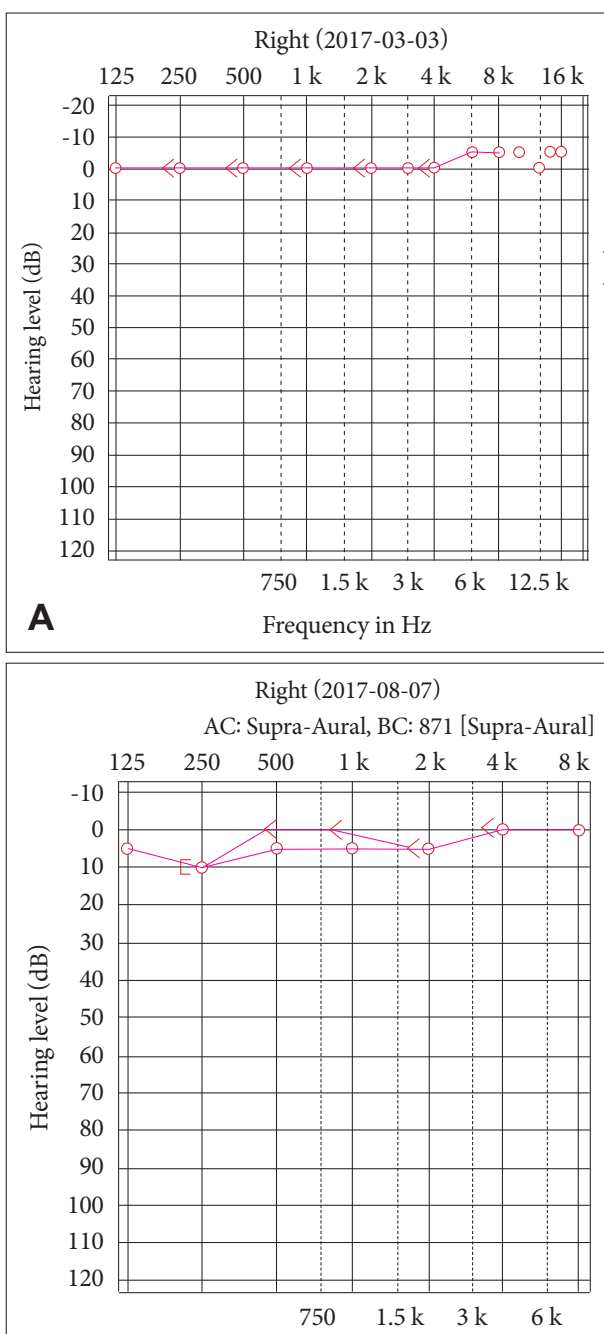

B

Frequency in $\mathrm{Hz}$
Left (2017-03-03)

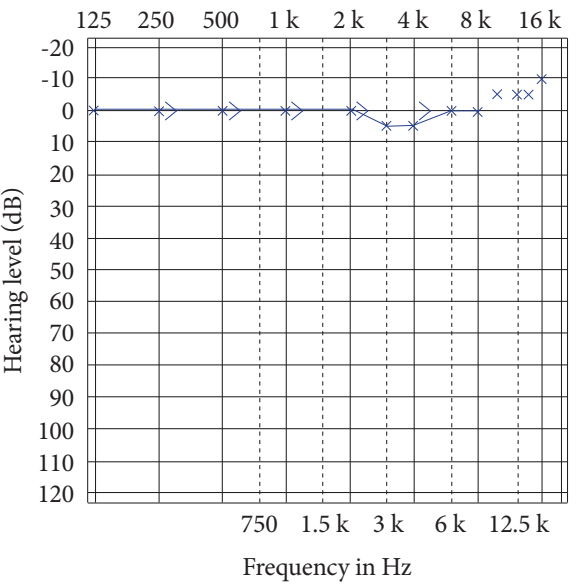

Left (2017-08-07)

AC: Supra-Aural, BC: 871 [Supra-Aural]

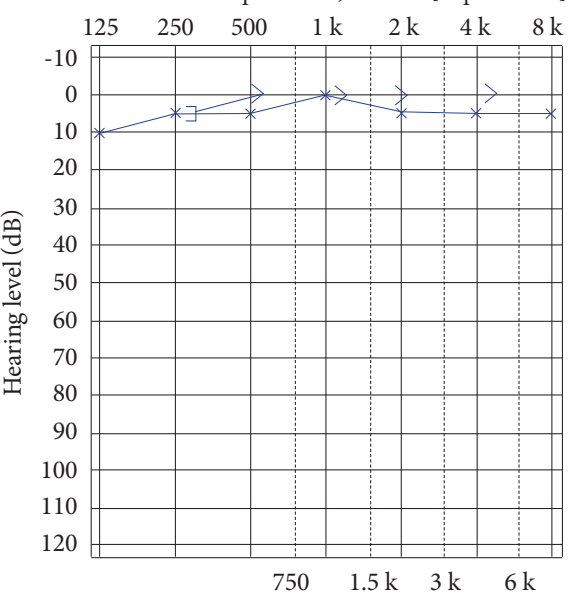

Frequency in $\mathrm{Hz}$
Figure 1. Pure tone audiometry performed on tinnitus-aggravation period. A: Initial outpatient department visit, B: Tinnitus-aggravation period. Slight threshold shift were observed in lower frequency areas of both ears. AC: air conduction, BC: bone conduction. 
Figure 2. Photographs of fundus. Moderate degree of papilledema are observed in both eyes (arrows).

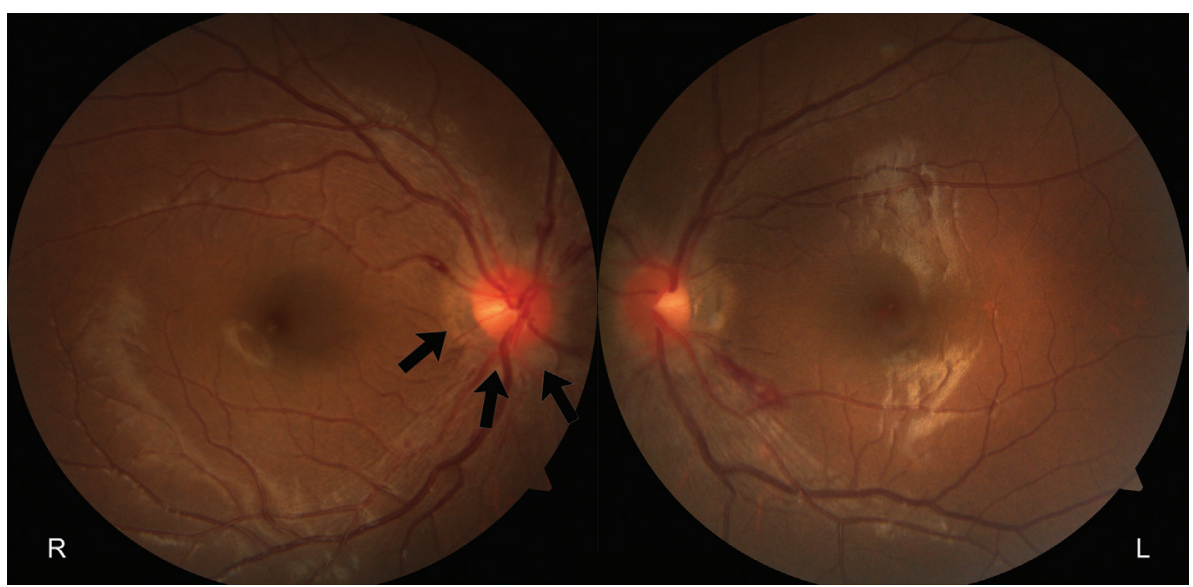

반응이 없었기 때문에 두개 내압 상승에 의한 박동성 이명이 의심되었다. 이를 확인하기 위해 안과에 의뢰하여 안저검사를 시행하였고 두개 내압 상승을 시사하는 유두의 부종이 확인되 었다(Figure 2). 이후 환자는 신경과로 전과되어 시행한 요추 천자(spinal tapping)검사에서 뇌척수액 압력이 $45 \mathrm{cmH}_{2} 0$ 로 측정되어 두개내고혈압이 확인되었고 두개 내압 상승의 원인을 찾기 위하여 시행한 brain MRI와 MRA 검사는 모두 정상으로 확인되어 특발성 두개내고혈압으로 최종 진단되었다. 또한 일반 혈액검사 및 말초혈액 도말검사에서 철결핍성 빈혈이 확인되었 고 원인 감별을 위해 위장관 내시경 및 산부인과 검진을 시행하 였고 철분 보충 치료를 시작하였다. 이와 함께 체중 감량, 저염 식이, 뇌압강하제인 carbonic anhydrase inhibitor (acetazolamide) $500 \mathrm{mg}$ bid 투여를 병행하였고 2개월 후 환자의 이명은 소실되어 현재까지 증상이 유지되고 있다.

\section{DISCUSSIONS}

박동성 이명은 발생 원인이 매우 다양하다. 크게 혈관성 원인 과 비혈관성 원인으로 분류되며 혈관성 이명은 동맥성과 정맥 성 원인으로 다시 나뉘어진다. 이 경우 대부분 혈류 증가 또는 혈관 내면의 협착이 이명 발생의 원인으로 알려져 있다(Mattox \& Hudgins, 2008). 적절한 기질적 원인을 확인하여 치료하면 이명의 완치가 가능하기 때문에 철저한 진단과 검사가 필요하 지만 박동성 이명의 약 $30 \%$ 에서는 그 원인이 알려져 있지 않 다(Sonmez et al., 2007).

정맥 기원의 박동성 이명은 두개내고혈압 및 두개 기저부 정 맥의 변이 등을 포함하며 두개내고혈압 환자의 최대 $65 \%$ 가 박 동성 이명을 경험한다고 한다(Skau et al., 2011). 두개내고혈압 은 뇌 내부의 공간을 점유하는 병변 혹은 정맥동의 혈전 등에 의해서도 유발될 수 있는데 잠재적으로 두 가지 모두 박동성 이 명을 발생시킬 수 있다. 두개내고혈압 중 뇌 내부의 구조적 이상
이나 종양 등 특별한 원인이 없이 두개 내압이 상승하여 두통, 오심, 구토, 시력감소, 복시, 어지럼증 및 박동성 이명을 보이는 경우를 특발성 두개내고혈압(idiopathic intracranial hypertension)이라 한다. 과거에는 이를 가성 뇌종양(psuedotumor cerebri), 또는 양성 두개내고혈압(benign intracranial hypertension)이라 불렀으며 뇌척수액 검사에서의 뇌압 상승 외에는 정 상 소견을 보이는 것이 특징이다(Skau et al., 2006).

박동성 이명은 특발성 두개내고혈압의 가장 흔한 증상이며 유일한 징후일 수도 있다. 또한 청력저하, 어지럼증, 이충만감 등 을 동반할 수 있기 때문에 대개 환자들은 이비인후과를 방문하 는 경우가 많다(Sismanis, 2011). 아직 이 질환의 정확한 병태생 리는 밝혀지지 않고 있으며 $90 \%$ 이상의 환자가 가임기의 비만 한 여성으로 가끔 V, VI, VII번 뇌신경의 마비를 동반하나 대부 분 특이한 신경학적 장애 없이 두개 내압 상승 소견을 보인다. 본 증례의 경우 신장 $170 \mathrm{~cm}$, 체중 $114 \mathrm{~kg}$, body mass index 39.4의 고도비만으로 특발성 두개내고혈압의 전형적인 양상을 보이고 있다. 이처럼 비만은 특발성 두개내고혈압의 주요 위험 인자로 제시되어 왔으며 가장 유력한 가설로 중심성 비만에 의 한 복강 내 압력 증가가 횡격막의 상승을 가져오면 이에 따라 흥 강 내압이 상승하여 뇌로부터 정맥 환류의 저항이 높아지고 이 로 인한 두개 내압의 상승이 제시되고 있다(Sugerman et al., 1997).

또한 초기 청력검사에는 나타나지 않았던 저음역대의 감각신 경성 난청이 이명이 악화된 후 발견되었는데 이러한 경도의 저 음역 청력저하는 저음역 이명에 의해 청력검사 시에 검사음이 잘 들리지 않게 되는 차폐효과(masking effect)로 설명 가능하 다(Sismanis, 1987). 또한 증가된 두개 내압으로 인한 청신경 및 뇌간의 직접적인 압박이 청력저하 및 현훈의 원인으로 지목되 고 있는데 그 근거로 Sismanis는 이러한 환자군의 $30 \%$ 정도에 서 비정상적인 청각유발반응(auditory-evoked response; prolonged interpeak latency)이 나타나는 것을 보고한 바 있다 
(Sismanis et al., 1990).

본 증례의 환자에서 나타난 철결핍성 빈혈은 이에 동반한 뇌 혈류량의 증가 및 혈액량의 증가로 두개 내압의 상승을 초래할 수 있으므로 빈혈의 유무를 반드시 확인하여야 하며 빈혈의 교 정만으로도 경우에 따라 뚜렷한 이명의 호전을 가져올 수 있다 (Stoebner et al., 1970). 또한 생리주기가 불규칙하거나 생리량 이 많은 경우 빈혈이 악화되기 때문에 생리주기에 따른 이명의 변화도 설명이 가능하다.

특발성 두개내고혈압의 확진을 위해서는 요추 천자를 통하 여 뇌척수액 압력이 $25 \mathrm{cmH}_{2} \mathrm{O}$ 이상임을 확인해야 하고 영상검 사를 통한 다른 뇌내 기질적 원인의 가능성을 모두 배제해야 한다. 본 증례에서 영상검사의 이상 소견은 발견되지 않았고 뇌 척수액 압력은 $45 \mathrm{cmH}_{2} 0$ 로 높게 측정되었다. 그러나 고가의 또 는 침습적인 검사를 시행하지 않고도 간단한 안저검사를 통해 유두 부종을 확인함으로써 두개 내압 상승을 확인할 수 있다. 또한 시야장애 등도 특발성 두개내고혈압에서 동반될 수 있기 때문에 우선적인 안과 협진이 이루어지는 것이 바람직하다. 측 두골 컴퓨터단층촬영 및 brain-MRI 등의 영상검사에서 구조 적 이상 소견이 없는 박동성 이명으로 특히 환자가 가임기의 젊은 비만 여성일 경우 안저검사로 유두부종의 소견을 확인함 으로써 특발성 두개내고혈압을 의심할 수 있고 뇌척수액 검사 를 통하여 이를 확진할 수 있다. 이러한 박동성 이명의 경우 체 중감량, 저염분 식이, acetazolamide의 투여로 효과적인 치료 가 가능하다. 우리나라에서는 서양에 비해 고도비만 환자가 적 기 때문에 특발성 두개내고혈압 유발 박동성 이명 환자는 드문 것으로 생각된다. 그러나 이비인후과적 영역 이외의 다른 기질
적 원인으로 인해 이명 증상이 나타나고 대부분의 환자가 이를 주소로 이비인후과를 처음으로 방문하는 경우가 많아 각별한 주의가 필요하다.

중심 단어 : 이명·특발성 두개내고혈압·비만.

\section{REFERENCES}

Mattox, D. E. \& Hudgins, P. (2008). Algorithm for evaluation of pulsatile tinnitus. Acta Oto-Laryngologica, 128(4), 427-431.

Sismanis, A. (1987). Otologic manifestations of benign intracranial hypertension syndrome: Diagnosis and management. The Laryngoscope, 97(8 Pt 2 Suppl 42), 1-17.

Sismanis, A. (2011). Pulsatile tinnitus: Contemporary assessment and management. Current Opinion in Otolaryngology and Head and Neck Surgery, 19(5), 348-357.

Sismanis, A., Callari, R. H., Slomka, W. S., \& Butts, F. M. (1990). Auditoryevoked responses in benign intracranial hypertension syndrome. The Laryngoscope, 100(11), 1152-1155.

Skau, M., Brennum, J., Gjerris, F., \& Jensen, R. (2006). What is new about idiopathic intracranial hypertension? An updated review of mechanism and treatment. Cephalalgia: An International Journal of Headache, 26(4), 384-399.

Skau, M., Sander, B., Milea, D., \& Jensen, R. (2011). Disease activity in idiopathic intracranial hypertension: A 3-month follow-up study. Journal of Neurology, 258(2), 277-283.

Sonmez, G., Basekim, C. C., Ozturk, E., Gungor, A., \& Kizilkaya, E. (2007). Imaging of pulsatile tinnitus: A review of 74 patients. Clinical Imaging, 31(2), 102-108.

Stoebner, R., Kiser, R., \& Alperin, J. B. (1970). Iron deficiency anemia and papilledema. Rapid resolution with oral iron therapy. The American Journal of Digestive Diseases, 15(10), 919-922.

Sugerman, H. J., DeMaria, E. J., Felton, W. L. 3rd., Nakatsuka, M., \& Sismanis, A. (1997). Increased intra-abdominal pressure and cardiac filling pressures in obesity-associated pseudotumor cerebri. Neurology, 49(2), 507-511. 